\title{
Reduced spiral ganglion neuronal loss by adjunctive neurotrophin-3 in experimental pneumococcal meningitis
}

\author{
Cornelia Demel', Tobias Hoegen ${ }^{1}$, Armin Giese ${ }^{2}$, Barbara Angele', Hans-Walter Pfister ${ }^{1}$ \\ , Uwe Koedel', Matthias Klein ${ }^{1 *}$
}

\begin{abstract}
Background: Hearing loss is a frequent long-term complication of pneumococcal meningitis (PM). Its main pathological correlate is damage to the organ of Corti and loss of spiral ganglion neurons. The only current treatment option is cochlear implants which require surviving neurons. Here, we investigated the impact of systemically applied neurotrophin-3 (NT-3) on long-term hearing loss and the survival of neurons.
\end{abstract}

Methods: Eighteen hours after infection with S. pneumoniae, C57BL/6 mice were treated with a combination of ceftriaxone with NT-3 or dexamethasone or placebo. Hearing, cochlear damage, and brain damage were assessed by audiometry and histology.

Results: The main findings from immunohistochemical visualization of neurotrophins (NT-3, BDNF) and their receptors (TrkB, TrkC, and p75) in the cochlea were (i) enhanced staining for the cell survival-promoting receptor TrkB and (ii) increased NT-3 staining in NT-3 treated mice, showing that systemically applied NT-3 reaches the cochlea. The major effects of adjunctive NT-3 treatment were (i) a reduction of meningitis-induced hearing impairment and (ii) a reduction of spiral ganglion neuronal loss. The efficacy of NT-3 therapy was comparable to that of dexamethasone.

Conclusion: Systemically applied NT-3 might be an interesting candidate to improve hearing outcome after pneumococcal meningitis.

\section{Introduction}

Despite calculated antibacterial therapy and supportive intensive care, bacterial meningitis remains a very serious infectious disease with approximately 1.2 million cases per year worldwide causing 135.000 deaths [1]. The most frequent causative pathogen in adults is Streptococcus (S.) pneumoniae, leading to death in $15-25 \%$ of cases [2]. Up to $50 \%$ of survivors suffer from long-term sequelae. Sensorineural hearing loss is one of the most prevalent acute and long-term complications. It can manifest as uni- or bilateral, and as mild to severe hearing impairment, affecting one fourth of survivors [2-4].

\footnotetext{
* Correspondence: matthias.klein@med.uni-muenchen.de 'Department of Neurology, Klinikum Grosshadern, Ludwig Maximilians University Munich, Marchioninistrasse 15, 81377 Munich, Germany Full list of author information is available at the end of the article
}

In the course of acute bacterial meningitis, infection spreads most likely from the subarachnoid space through the cochlear aqueduct, reaching the perilymphatic spaces and causing suppurative labyrinthitis [5-7]. A massive immune response directed against the bacteria leads to collateral damage of the cochlea's own tissue $[8,9]$. Histopathological findings show a bloodlabyrinth barrier disruption, damage to the organ of Corti, and destruction of spiral ganglion cells in the acute phase [2,10-14]. Loss of spiral ganglion neuronal cells as well as fibrocytic reorganisation of the perilymphatic spaces, leading to labyrinthitis ossificans, are noted as long-term residues $[5,15]$. In addition to the inflammatory response, direct bacterial toxicity may be a factor driving cochlear damage in meningitis. E.g., intracisternal inoculation of strains deficient in pneumolysin
C Biomed Central 
production is associated with significantly lower cochlear injury [16].

Currently, the only treatment option for severe long term hearing loss in pneumococcal meningitis is surgical implantation of a cochlear implant $[17,18]$. The efficacy of cochlear implant surgery depends on multiple factors, which include cognitive measures, proper surgical insertion, and the length of time after onset of deafness [19-21]. Moreover, at least a critical number of neurons seem necessary for proper functioning of a cochlear implant. This is underscored by the finding of a recent study that all patients who benefited from cochlear implantation had at least some spiral ganglion neuronal cells (SGCs) remaining (whereas peripheral nerve fibres or hair cells were completely absent in most patients) [22]. Bacterial meningitis can result in a dramatic reduction in the number of SGCs [6]. Additionally, the GC population was found to decline (further) over time after meningitis $[23,24]$. Therefore, therapeutic approaches to protect neurons from cell death during and after meningitis might have the potential to improve the efficacy of cochlear implants.

The neurotrophins are a group of proteins that induce survival, differentiation and neurite outgrowth. Two such neuroprotective agents, neurotrophin-3 (NT-3) and brain-derived neurotrophic factor (BDNF), play a significant role in the cochlea [25]. They are released by cochlear sensory cells and act via tyrosine kinase receptors (TrkB and TrkC) and p75-receptors that are expressed by spiral ganglion neuronal cells $[26,27]$. Studies using knock-out mice lacking either BDNF, NT-3, or both neurotrophins have demonstrated that both neurotrophic agents play a crucial role in the development and maintenance of spiral ganglion neuronal cells $[28,29]$. Administration of neurotrophin via miniosmotic pumps, drug-eluting cochlear implants or viral vectors in animal studies have shown promising results in protecting auditory neurons and even in partly counteracting hearing loss $[17,30-33]$. In this study, we investigated the impact of systemically administered NT-3 on the preservation of cochlear neurons and hearing loss. Furthermore, we investigated the impact of NT-3 on neurologic outcome in a mouse model of experimental pneumococcal meningitis. Adjunctive therapy with NT-3 was compared to adjunctive dexamethasone treatment which has been recommended for adjunctive treatment of pneumococcal meningitis in adults [34,35].

\section{Methods}

\section{Mouse model of pneumococcal meningitis}

A well-characterized mouse model of pneumococcal meningitis was used in this study [36]. The model has been developed in C57BL/6 mice which are widely used for studies of cerebral infection and for studies on acquired hearing loss. C57BL/6 mice, however, carry the AHL locus for genetic hearing loss $\left(C d h 23^{a h l}\right)$ [37]. All animals were of the same age (4-6 weeks), at a time point months before age-related hearing loss occurs in these mice [38]. In brief, meningitis was induced by transcutaneous intracisternal injection of $15 \mu \mathrm{l}$ of a bacterial suspension containing $10^{6}$ colony forming units $(\mathrm{cfu}) / \mathrm{ml}$ of S. pneumoniae (SP) D39 or placebo under short-term anaesthesia with enflurane. Mice were weighed, put into cages, allowed to wake up and fed with a standard diet and water ad libitum. Eighteen hours after infection, when all mice showed clinical signs of meningitis, intraperitoneal therapy with ceftriaxone was begun and continued for a total of 4 days. Furthermore, animals received adjunctive therapy or placebo (see experimental groups). Two weeks after infection, mice were deeply anaesthetized with ketamine and xylazine (SIGMA, St. Louis, MO, USA) and perfused transcardially with $15 \mathrm{ml}$ of ice-cold phosphate buffered saline (PBS) containing $10 \mathrm{U} / \mathrm{ml}$ heparin. Temporal bones and brains were dissected, fixed in $4 \%$ formalin, decalcified in PBS containing 10\% EDTA (SIGMA, St. Louis, MO, USA), and embedded in paraffin. All animal experiments were approved by the government of Upper Bavaria, Germany.

\section{Experimental groups in the mouse model}

The following groups were investigated: (i) mice intracisternally injected with $15 \mu \mathrm{l}$ sterile phosphate-buffered saline (PBS) (CON; $\mathrm{n}=8)$; (ii) mice intracisternally injected with SP, treated with $100 \mathrm{mg} / \mathrm{kg}$ ceftriaxone (Roche, Grenzach-Wyhlen, Germany) daily for 4 days and $0.5 \mathrm{ml}$ isotonic saline every 2nd day for 2 weeks (PLC, $\mathrm{n}=16$ ); (iii) mice intracisternally injected with SP, treated with $100 \mathrm{mg} / \mathrm{kg}$ ceftriaxone daily for 4 days and $0.5 \mathrm{mg} / \mathrm{kg}$ dexamethasone (Merck, Darmstadt, Germany) every $8 \mathrm{~h}$ for a total of 4 days (DEX, $\mathrm{n}=12$ ); (iv) mice intracisternally injected with SP, treated with $100 \mathrm{mg} / \mathrm{kg}$ ceftriaxone daily for 4 days and $25 \mu \mathrm{g} / \mathrm{kg}$ Neurotrophin-3 (R\&D Systems, Wiesbaden, Germany) every 2nd day for 2 weeks $(\mathrm{NT}-3, \mathrm{n}=11)$. Infected placebo-treated mice (PLC) were compared with uninfected mice $(\mathrm{CON})$, showing successful infection and development of meningitis and meningitis-associated hearing loss. To detect a possible adjunctive treatment effect, animals who received adjunctive therapy with dexamethasone (DEX) or neurotrophin-3 (NT-3) were compared with placebotreated mice (PLC) and with each other.

\section{Clinical assessment of mice}

Animals were investigated clinically before infection, $18 \mathrm{~h}, 42 \mathrm{~h}$, and 2 weeks after infection. Clinical scores (CS) were determined as previously described reaching 0 points if there were no clinically noticeable signs of 
disease and 12 points if the animal died [39]. In brief, the following criteria were assessed: (i) beam balancing, (ii) postural reflexes, (iii) piloerection, (iv) epileptic seizures, and (v) level of consciousness. For determination of explorative activity, each mouse was put in the middle of a $42 \times 42 \mathrm{~cm}$ box divided into 9 squares and allowed to explore the box for two minutes. The number of squares which the mouse passed through within the two minutes time interval was counted.

\section{Determination of hearing}

Hearing was determined by auditory brain-stem responses (ABRs) at the end of the experiment. Mice were anaesthetized intraperitoneally with $100 \mathrm{mg} / \mathrm{kg}$ ketamine and $5 \mathrm{mg} / \mathrm{kg}$ xylazine. Needle electrodes were placed over each mastoid (negative pole), the vertex (positive pole), and the neck (reference). Impedances were controlled to be below $5 \mathrm{k} \Omega$. Square-wave click impulses (duration: $100 \mathrm{~ms}$; frequency: $20 \mathrm{~Hz}$ ) and tone bursts of 1 and $10 \mathrm{kHz}$ (duration: $4 \mathrm{~ms}$; frequency: $23.4 \mathrm{~Hz}$ ) were delivered by earphones (E-A-RTONE3A, Aearo Company, Indianapolis, IN, USA). ABRs were amplified (x250.000), band-pass filtered (150-10,000Hz), and averaged $(\mathrm{n}=1000)$ using a Neuroscreen Plus (Jaeger-Toennies, Freiburg, Germany). To determine the hearing threshold, we started with an impulse of $105 \mathrm{~dB}$ Sound Pressure Level (SPL) and reduced the intensity in $5 \mathrm{~dB}$ SPL steps. The lowest stimulus intensity that elicited visual ABRs was considered to be the hearing threshold. If a response could not be elicited at $105 \mathrm{~dB}$ SPL, stimulus intensities of up to $130 \mathrm{~dB}$ SPL were tested.

\section{Histologic assessment of cochleae}

For histological analysis, midmodiolar sections (thickness $7 \mu \mathrm{m}$ ) of mouse temporal bone were deparaffinized, rehydrated, and stained with Mayer's haematoxylin and eosin (H\&E; MERCK, Darmstadt, Germany). Sections were digitized using an Olympus BX51 microscope (Olympus Optical, Hamburg, Germany), connected to a camera (Moticam 5000, Motic Deutschland GmbH, Wetzlar, Germany). Two sections of each cochlea were analyzed and the mean was calculated for statistics.

For determination of the spiral ganglion neuronal density in the cochlea, the area of each spiral ganglion was measured (Image Tool Version 3.00, University of Texas Health Science Center, San Antonio, TX, USA) and morphologically intact spiral ganglion neurons (criteria: round cell body containing a nucleus and homogenous cytoplasm) were counted within this area.

A regular cochlear finding 2 weeks after pneumococcal meningitis is fibrocytic occlusion of the scala tympani, indicating early labyrinthitis ossificans. The degree of occlusion was evaluated by measurement of the occluded area of the basal turn of the tympanic scala (Image Tool Version 3.00, University of Texas Health Science Center, San Antonio, TX, USA). The occluded area was expressed as a percentage to the total area of the basal scala tympani.

The integrity of the organ of Corti was evaluated as (i) existing and intact, or (ii) absent or respectively damaged. The integrity of the organ of Corti was defined as intact inner and outer hair cells as well as an intact architecture of supporting cells.

\section{Immunohistochemical detection of neurotrophins and neurotrophin receptors}

Cochleae were stained for NT-3 and BDNF as well as their receptors $\operatorname{TrkB}$, TrkC (both inducing neuroprotective effects on neurons) and p75 (inducing apoptosis in neurons) using immunohistochemistry. Sections were deparaffinized and placed in a microwave for boiling in $10 \mathrm{mM}$ citrate buffer ( $\mathrm{pH}$ 6) for antigen retrieval. Endogenous peroxidases were blocked by incubation with $0.3 \%$ hydrogen peroxide in methanol (MERCK, Hohenbrunn, Germany). Sections were incubated with one of the following primary antibodies: (i) rabbit polyclonal anti-NT3 (1:500 in blocking solution, Alomone Labs Ltd, Jerusalem, Israel); (ii) rabbit polyclonal anti-BDNF (1:500 in blocking solution, Alomone Labs Ltd, Jerusalem, Israel); (iii) rabbit polyclonal anti-TrkB (1:500 in blocking solution, Novus Biologicals Inc., Littleton, CO, USA); (iv) goat monoclonal anti-mouse TrkC (1:200 in blocking solution, R\&D Systems, Wiesbaden, Germany); (v) rabbit polyclonal anti-human p75 NTR (1:200 in blocking solution, Alomone Labs Ltd, Jerusalem, Israel) or (vi) blocking solution without primary antibody (negative control) in a humidified chamber overnight. Then, sections were incubated with secondary antibodies (biotinylated anti-rabbit IgG made in goat or anti-goat IgG made in horse according to the primary antibody used; both 1:200, Vector Labs, Burlingame, CA, USA). Binding of the secondary antibody was visualized with streptavidin horse-radish peroxidase (DAKO, Hamburg, Germany) and diaminobenzidine (Vector Labs, Burlingame, CA, USA), which yields a brown reaction product. Between all reaction steps, slides were rinsed with $0.1 \mathrm{M}$ PBS ( $\mathrm{pH} 7.4)$. Counterstaining was performed using Mayer's hematoxylin.

For assessment of immunohistochemical staining patterns, the most basal spiral ganglion was digitized. Pictures were blinded and printed on $20 \times 30 \mathrm{~cm}$ color prints. Then, four reviewers (one professor of neuropathology, one assistant professor of neurology, and two residents of neurology with experience in neuropathology) independently grouped the printouts according to (i) homogeneity of the neuronal staining, (ii) intensity of the neuronal staining, and (iii) intensity of extracellular 
staining. A group was considered to be identified successfully if $>80 \%$ of blinded slides were grouped together correctly.

\section{Histologic assessment in the brain}

For histological analysis, 7- $\mu \mathrm{m}$-thick hippocampal sections of mouse brains were used. For assessment of general brain pathology, sections were stained with Mayer's haematoxylin and eosin (H\&E), Prussian blue (MERCK, Darmstadt, Germany) (detection of iron as a marker for residues of parenchymal hemorrhages), glial fibrillary acidic protein (GFAP, detection of astrocyte activation (rabbit GFAP polyclonal, 1:3000, DAKO, Hamburg, Germany), and neurofilament and amyloid precursor protein (APP, detection of axonal injury, Neurofilament monoclonal, 1:500, DAKO; APP A4 monoclonal, 1:100, Chemicon, Billerica, MA, USA; secondary antibody: swine anti-rabbit biotinylated, concentration 1:150, DAKO, Hamburg, Germany, visualization with streptavidin-horse radish peroxidase and diaminobenzidine). Activated (GFAP-positive) astrocytes (appearing with a round nucleus and more than two GFAP-positive processes) were counted within predetermined areas (cortex and hippocampus).

\section{Statistical analysis}

All experimental procedures were performed in a blinded fashion. Data were analyzed with SYSTAT 9 (SPSS, Chicago, IL, USA) using a t-test for independent variables. $\mathrm{P}<0.05$ was considered significant. A Bonferroni correction was used to address the problem of multiple comparisons. Correlation analyses were performed according to Spearman. Data are displayed as mean \pm standard deviation (SD).

\section{Results}

\section{Clinical characteristics of meningitis}

At 18 hours after infection, when treatment was begun, all infected mice had developed clinical signs of disease such as weight loss, an increased clinical score and reduced explorative activity. Within the next 24 hours following the start of the antibiotic therapy, the infected mice improved. By two weeks after infection, the clinical score of PLC mice almost completely resolved despite slight motor deficits and a reduced explorative activity (Figure 1). Mortality rates were similar in all groups (mortality PLC 4/16, NT-3 3/11, DEX 2/12); motor deficits and explorative activity did not differ between PLC, DEX, and NT-3.

Uninfected control animals $(\mathrm{CON})$ that received intracisternal sterile PBS also showed a slight decrease of explorative activity, possibly due to a combination of a mild traumatic effect and/or habituation. However, their clinical scores were not altered, and they did not show signs of infection (such as pilo-erection), meningeal irritation or neurologic deficits.

\section{Impact of adjunctive NT3 and dexamethasone on hearing} thresholds (HT)

Two weeks after infection, infected placebo-treated mice showed a significant elevation of hearing thresholds. An elevation of hearing thresholds was especially noted for high frequency hearing $(10 \mathrm{kHz})$. This reflects the circumstance that cochlear damage was worst in the basal turn.

Adjuvant therapy with NT-3 as well as dexamethasone mildly improved hearing outcome at two weeks after infection. (Figure 2)

\section{Impact of NT-3 and dexamethasone on cochlear spiral ganglion neuronal densities and cochlear occlusion} Meningitis led to damage of the organ of Corti, fibrocytic occlusion of the scala tympani, and loss of neurons in the basal spiral ganglion two weeks after infection (CON vs. PLC, Figure 3). The morphology of the organ of Corti was severely damaged or completely absent two weeks after infection with bacterial meningitis (CON vs. PLC: $0 \%$ vs. $54 \%$ (percentage of destroyed or completely absent organs vs. total number of investigated organs of Corti)). Adjuvant treatment, neither with NT-3 nor with dexamethasone, resulted in preservation of the organ of Corti (NT-3 29\%, DEX 54\% (destroyed or completely absent/total number of investigated organs of Corti)).

There was a significant decline of neuronal density in the basal spiral ganglion of infected mice (PLC) compared to uninfected controls (70\%). Neuronal densities in the basal spiral ganglion correlated inversely with high frequency hearing thresholds $\left(\mathrm{r}^{2}=0.51\right)$. Adjuvant therapy with NT-3 and dexamethasone led to a reduced loss of intact neurons in the spiral ganglion in comparison with the placebo group (Figure 4A).

Within infected mice, it was mainly the basal scala tympani that was obliterated with loose connective tissue. The mean occluded area in infected and placebotreated animals (PLC) was $75.1 \% \pm 27.52 \%$. In contrast, the scala media (endolymphatic space) and the scala vestibuli did not show occlusions on a regular basis. There was no significant difference in regard to occlusion among the infected groups (Figure 4B). In summary, our data suggest that the hearing protective effects of both NT-3 and dexamethasone are mediated by a reduced loss of spiral ganglion neuronal cells.

\section{Neurotrophins and their receptors in the spiral ganglion}

Two weeks after infection, there was a reduced number of intact neurons in the basal spiral ganglion of infected mice, which were more heterogeneously stained for neurotrophin NT-3 and BDNF than those of healthy control animals. All NT-3-treated mice showed an additional 


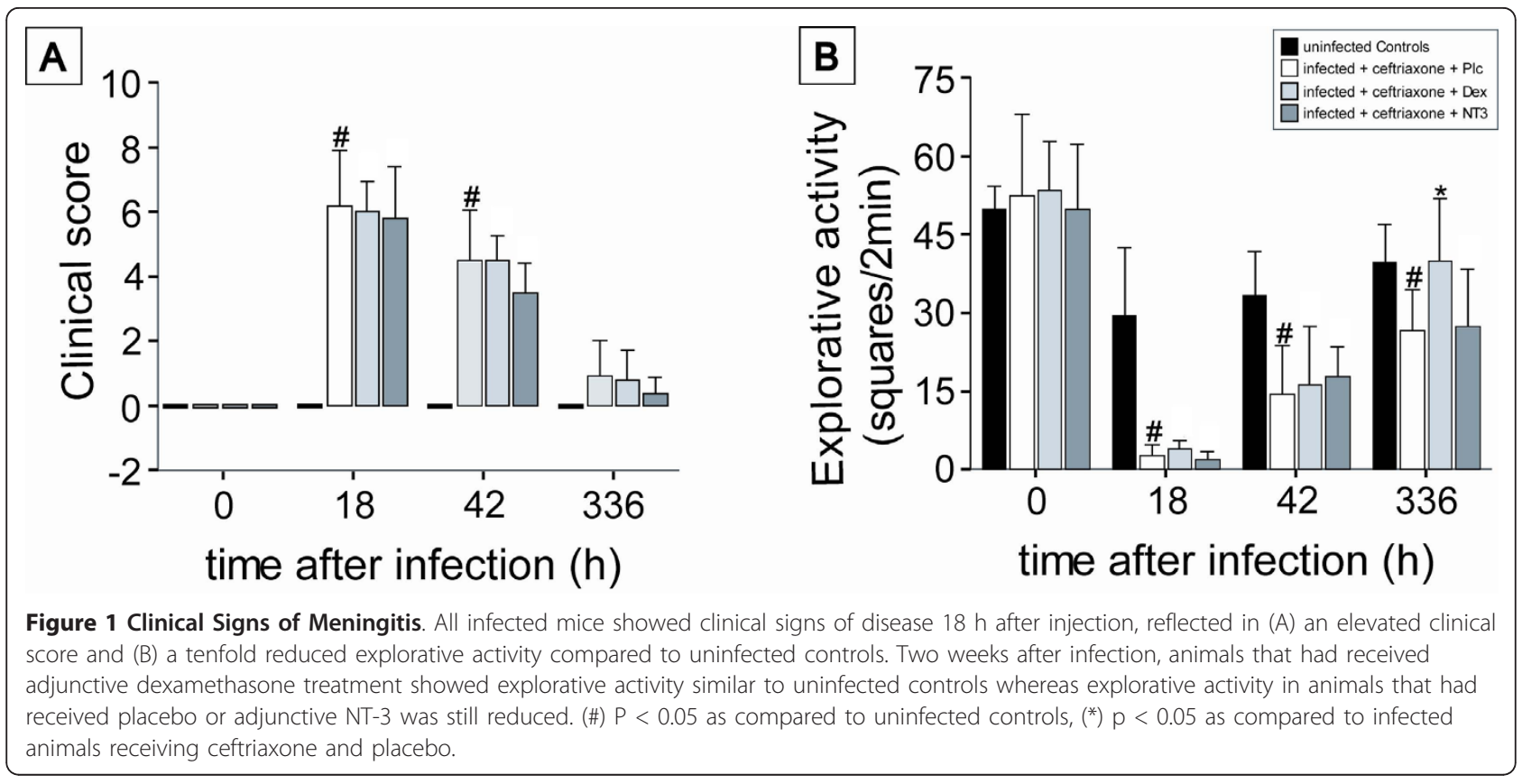

diffuse staining for NT-3 in the basal spiral ganglion that was not detected in any other group, indicating that systemically applied NT-3 reached the cochlea.

Whereas uninfected controls stained homogeneously for TrkB, a more intense staining of most neurons was found in infected animals. This finding could possibly reflect an up-regulation of TrkB to increase the neuron's opportunity to survive a situation with decreased neurotrophin levels (Figure 5). The p75-positive neurons of uninfected controls and infected mice showed no difference in staining pattern; in addition, staining patterns for TrkC and BDNF were not altered between the groups (not shown).

Morphological changes in the cortex and hippocampus An elevated number of GFAP-positive astrocytes was found in the cortex of infected mice (PLC), reflecting activation of astrocytes as an indicator of former brain
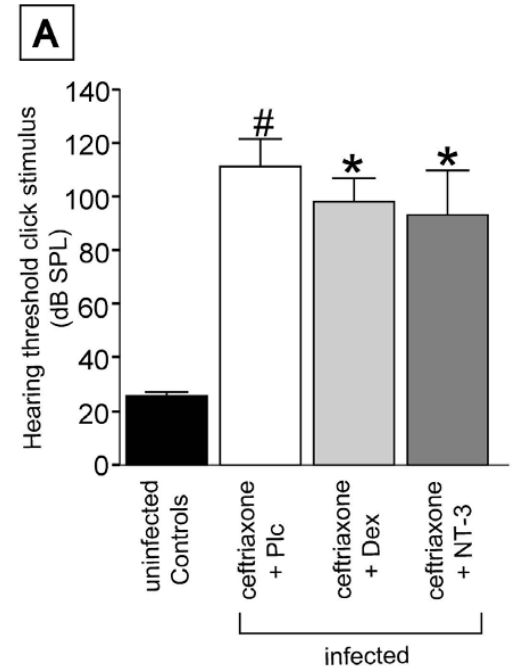
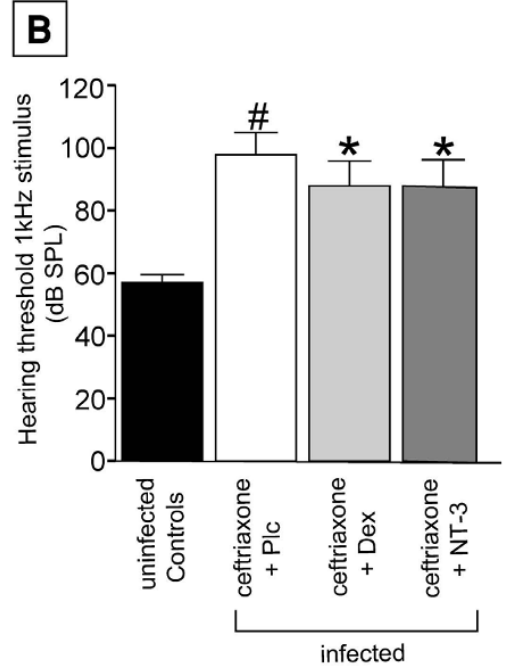
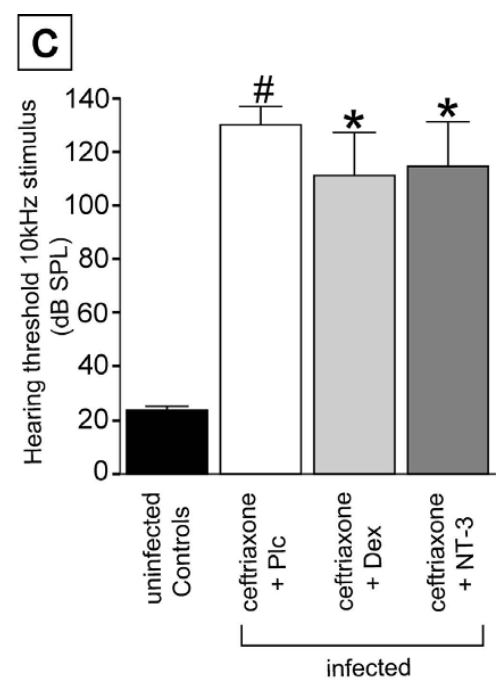

Figure 2 Adjunctive dexamethason and NT-3 decrease hearing loss. Mice were assessed for (A) click stimuli, (B) low frequency hearing (1 kHz stimuli), and (C) high frequency hearing (10 kHz stimuli). In infected animals, a significant increase of hearing thresholds was observed. The elevation of hearing thresholds was most severe for high frequency hearing. Adjunctive treatment with dexamethasone or NT-3 improved hearing significantly compared to mice treated with ceftriaxone plus placebo. There was no difference between dexamethasone and NT-3 treated animals. (\#) $\mathrm{P}<0.05$ as compared to uninfected controls, $\left(^{*}\right) \mathrm{p}<0.05$ as compared to infected animals receiving ceftriaxone and placebo. 

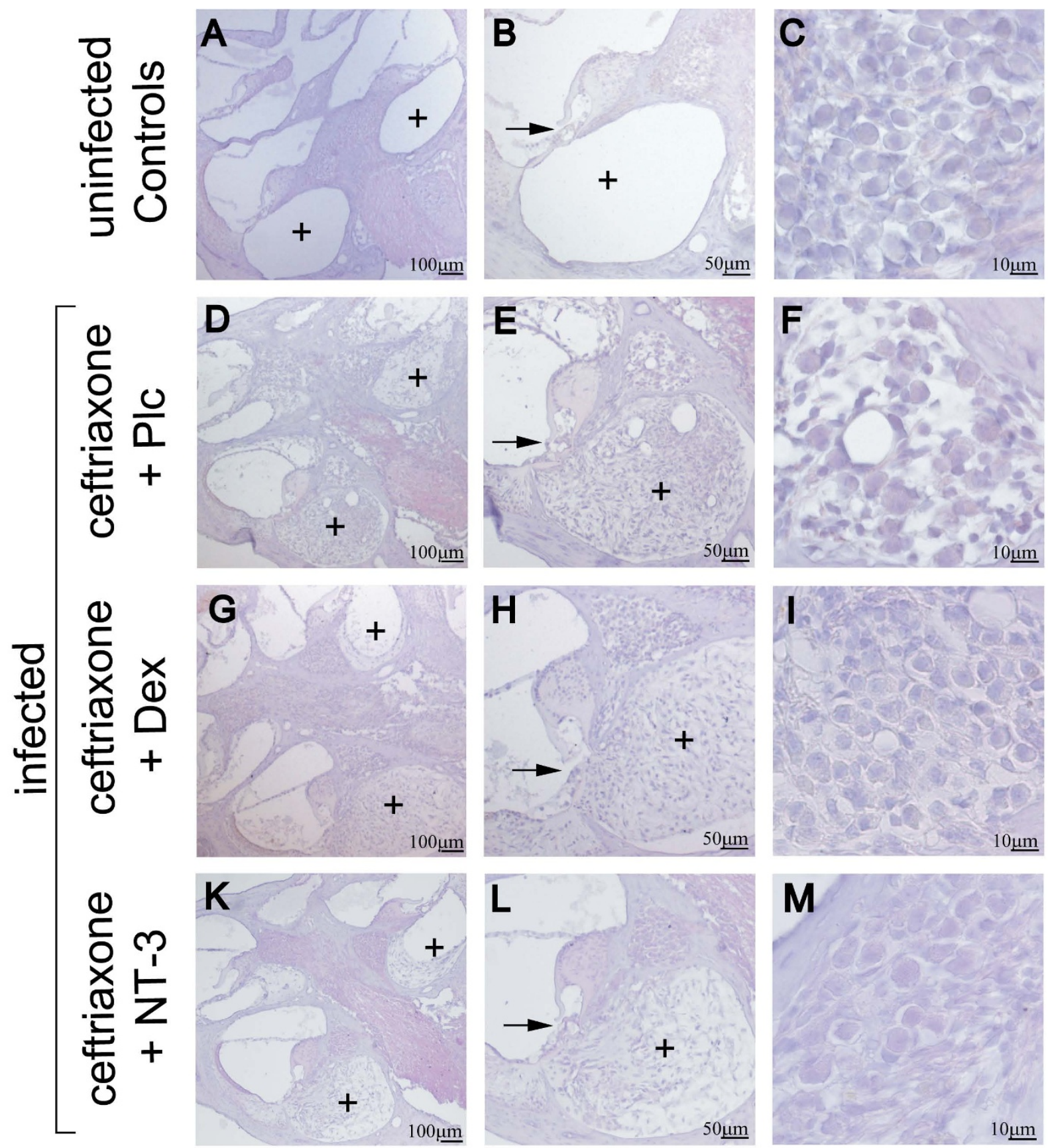

Figure 3 Pathologic alterations in the cochlea. (A-C) Cochleae of uninfected control animals showed an intact cochlear architecture (A, B) with a patent scala tympani $(+)$ and $(C)$ a dense population of neurons in the spiral ganglion. In infected animals that were treated with ceftriaxone and placebo, ( $D$ and $E)$ dense fibrocytic occlusion of the scala tympani $(+)$ was observed, $(E)$ the organ of Corti $(\rightarrow)$ appeared destroyed, and $(F)$ neuronal densities were decreased. Adjunctive treatment with $(G, H$, and I) dexamethasone or $(K, L$, and $M)$ NT-3 did not lead to significant changes in $(G, H, K$, and $L)$ fibrocytic cochlear occlusion or damage to hair cells but (I and $M)$ both therapies rescued neuronal ganglion cells from death, reflected in less neuronal loss. The morphology of the cochlea did not differ between animals treated with dexamethasone or NT-3. Staining was performed with hematoxylin and eosin. 


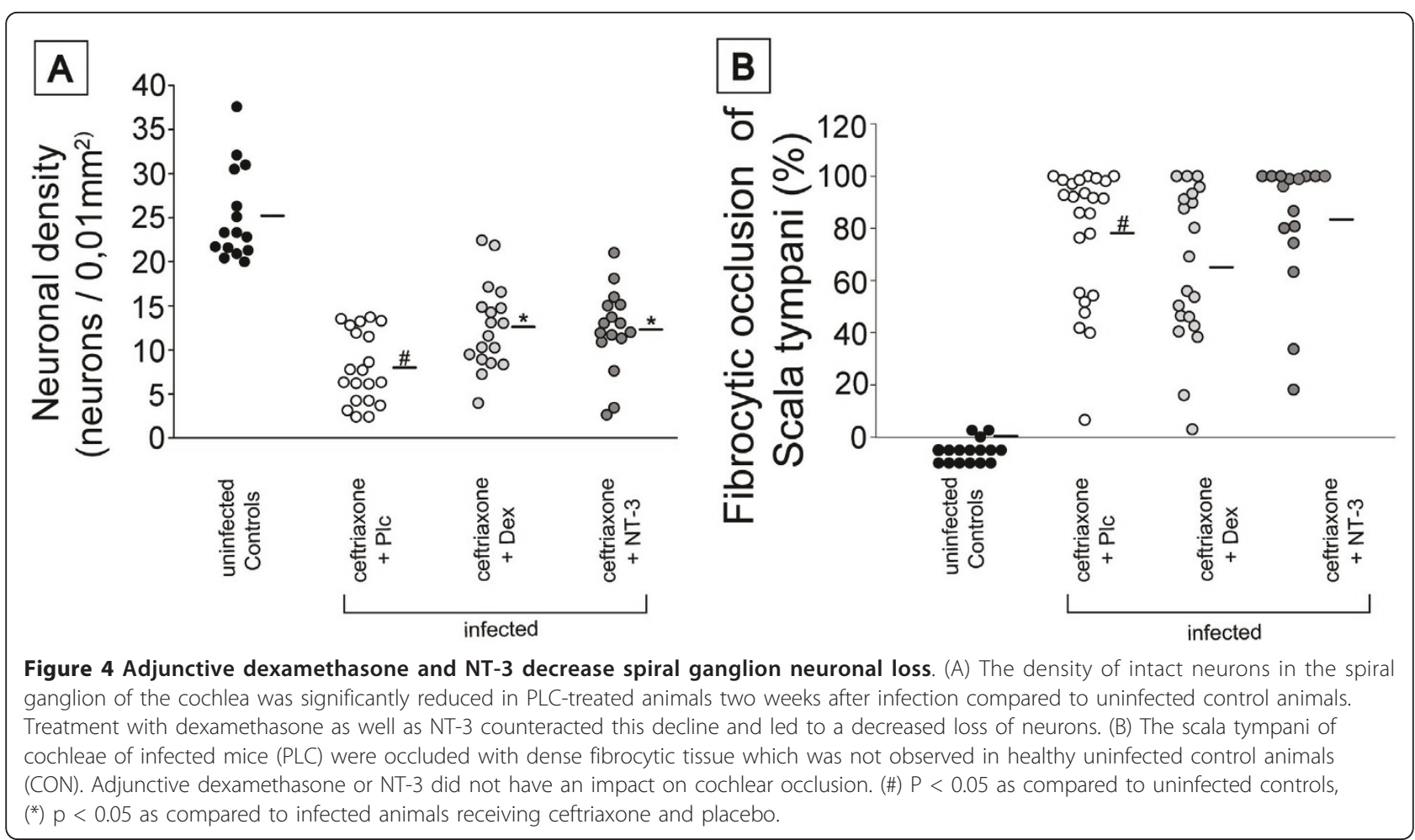

damage (CON vs. PLC: $12.7 \pm 11.2$ astrocytes $/ \mathrm{mm}^{2}$ vs. $88.9 \pm 57.5$ astrocytes $\left./ \mathrm{mm}^{2}, \mathrm{p}=0.003\right)$. There were no significant differences between the various treatment groups (NT-3 $55.5 \pm 28.3$ astrocytes $/ \mathrm{mm}^{2}$, DEX $116.3 \pm$ 51.5 astrocytes $/ \mathrm{mm}^{2}$ ) (Figure 6). Signs of previous parenchymal bleeding were absent (negative staining for iron). We also did not find pathological changes suggestive of necrosis or axonal injury in hippocampal or cortical areas two weeks after infection (data not shown).

\section{Discussion}

In this study, a mouse model of pneumococcal meningitis was used that featured all typical clinical and histomorphological findings of meningitis-associated labyrinthitis and hearing loss to study the impact of adjunctive neurotrophins on cochlear damage. We demonstrated that (i) intraperitoneally applied NT-3 reached the cochlea, (ii) adjunctive NT-3 treatment led to a significant decrease of spiral ganglion neuronal damage and hearing loss, (iii) the effect of NT-3 therapy was comparable to the benefit of adjunctive therapy with dexamethasone, and (iv) changes in brain pathology could not be observed after treatment with NT-3.

Two weeks after infection we observed meningitisassociated morphological changes in the cochlea, namely fibrocytic occlusion of the scala tympani, damage to and often loss of the organ of Corti, as well as a significant decline of neurons in the spiral ganglion. The morphological alterations dominated in the basal turn of the cochlea, where high frequency hearing is localized. This was associated with pronounced high frequency hearing impairment as measured with auditory brainstem responses. These findings are similar to previous experimental observations and data from humans with bacterial meningitis, suggesting a spread of the infection from the brain to the inner ear via the cochlear aqueduct that enters the basal turn of the scala tympani [2,23].

Our immunohistochemical findings indicate that intraperitoneally applied NT-3 actually reached the area of interest in the cochlea. A previously published study described findings consistent with our study: After systemic application of NT-3 (via a subcutaneous Alzet micro-osmotic pump) neuroprotective effects were noticed in the dorsal root ganglia [40]. This demonstrates that NT-3 can pass the blood-labyrinth-barrier (in contrast to BDNF that has a larger molecular size), and this led us to test the effect of NT-3 in our mouse model of meningitis-associated hearing loss [41]. Another possible circumstance that could have facilitated the passage of NT-3 into the cochlea in our model is disruption of the blood-labyrinth barrier that occurs during the course of acute bacterial meningitis [5]. Importantly, systemic application of NT-3 does not require specific equipment as is the case for neurotrophins that are applied locally 


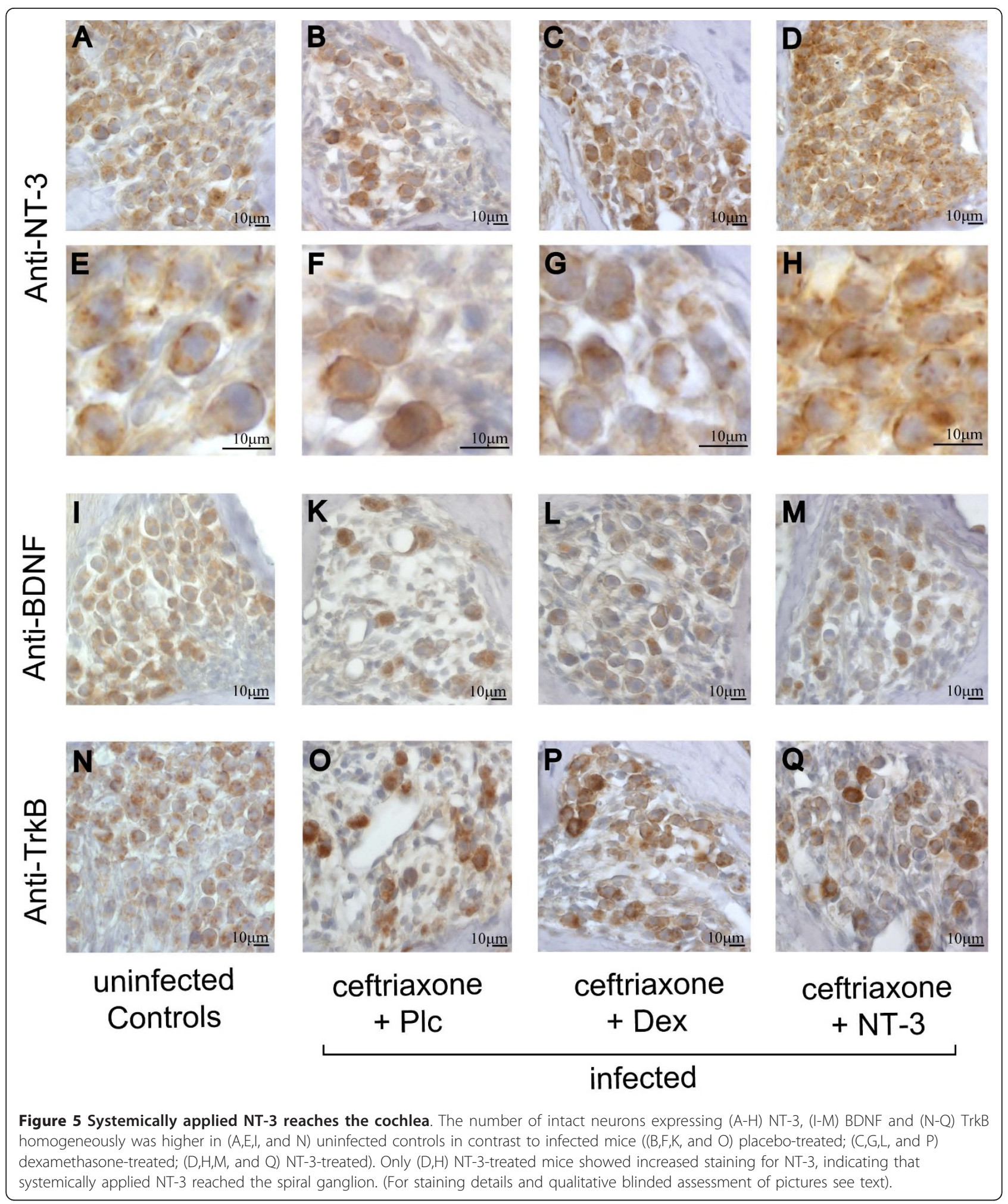



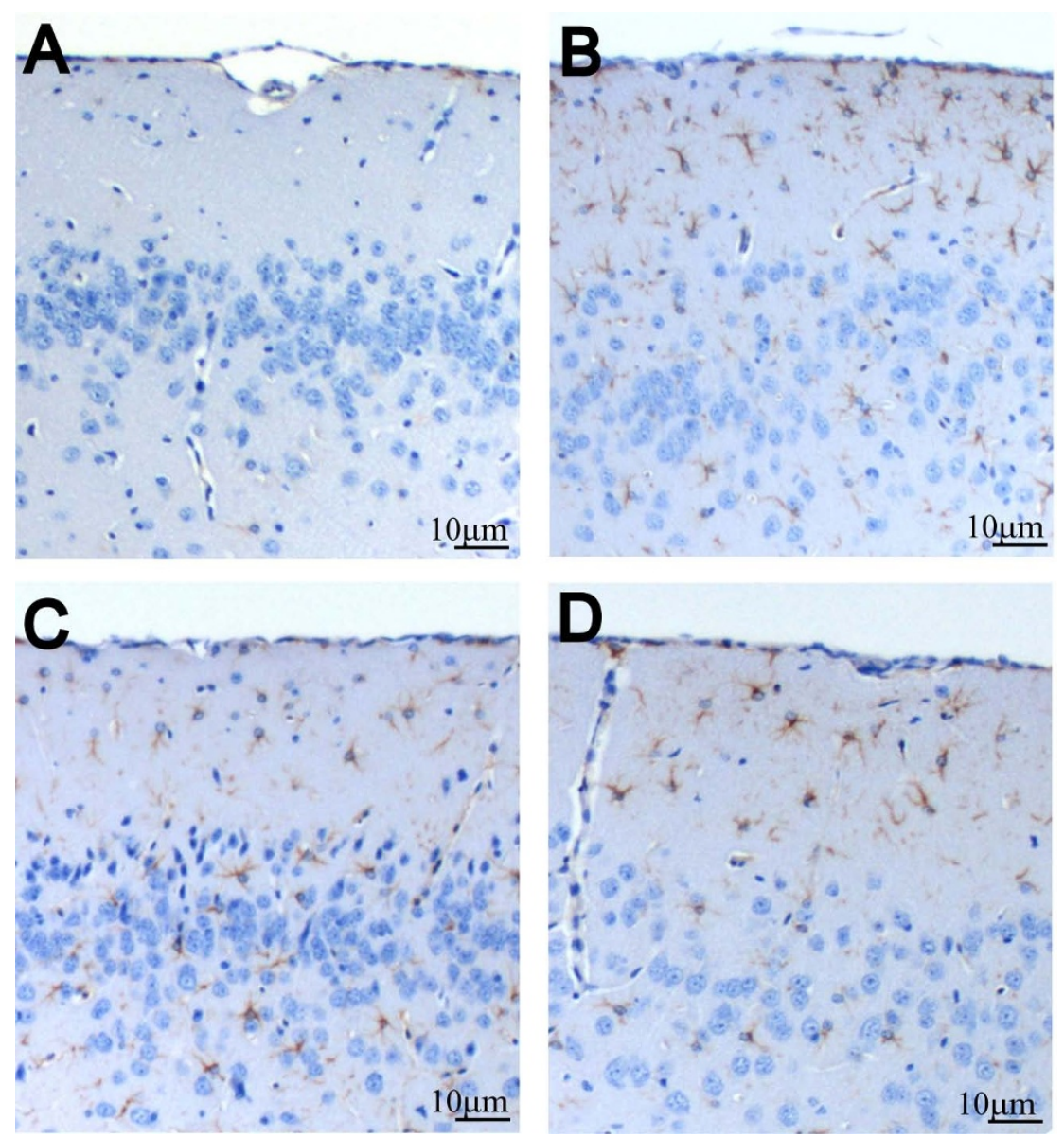

Figure 6 Astrocyte activation after meningitis. GFAP-positive astrocytes were not seen (A) in brains of uninfected control mice. In contrast (B-D) in brains of infected mice, a high density of GFAP-positive astrocytes in the cortex reaching far into the superficial layer was observed. (B) Compared to infected placebo-treated animals, this was not altered by adjunctive treatment with (C) dexamethasone or (D) NT-3. GFAP staining (brown).

via mini-osmotic pumps, viral vectors or drug-eluting electrodes; and it does not bear the risk of local infection [42].

Adjuvant NT-3 led to a reduced loss of neurons in the spiral ganglion and lowered hearing loss after meningitis. A reduction of spiral ganglion neuronal loss through adjunctive NT-3 has not been previously shown in bacterial meningitis-associated labyrinthitis. Our data is strengthened by a recent study that demonstrated that NT-3 can preserve cochlear spiral ganglion neurons after ototoxic hair cell damage when locally applied [18]. Hair cell damage is a predominant correlate of longterm meningitis-associated hearing loss and was also present in our model. Possibly this contributes to the loss of neurons in the ganglion after meningitis through reduced depolarization of cells followed by neuronal inactivity and neuronal death $[12,43]$. Furthermore, a decline of hair cells could lead to a reduced supply of BDNF and NT-3, necessary for neuronal survival [44].
This might explain the neuroprotective effect of exogenous NT-3 administration after meningitis. Protection of neurons in the spiral ganglion after meningitis is important, since a critical number of surviving neurons are a prerequisite for the functioning of cochlear implants, which currently represents the only available treatment option for sensorineural hearing loss. Furthermore, NT-3 not only reduced neuronal degeneration but even led to a reduction of hearing loss. Therefore, systemic adjuvant therapy with NT-3 might be an option for co-treatment of patients with pneumococcal meningitis.

Systemic administration of neurotrophins can lead to side effects. However the complete range of side effects cannot be predicted at present, because of a lack of experience and a lack of knowledge of the role of neurotrophins in certain systemic diseases: Neurotrophins have been shown to be present constitutively in the blood, and to be elevated in certain pathologic conditions. E.g., high levels of neurotrophins have been 
reported in patients with rheumatoid arthritis, systemic lupus erythaematosis, allergic disease, or asthma as well as type 1 diabetes and metabolic syndrome [45-48]. In vitro, an elevation of neurotrophins in response to proinflammatory cytokines has been found, suggesting a possible link between neurotrophins and inflammatory processes [49]. So far, it is suspected that systemic administration of TrkB agonists can lead to anorexia and weight loss, and systemic therapy with nerve growth factor (NGF) has been shown to evoke myalgias and arthralgias [50,51]. To date, systemic neurotrophin-3 has only been applied to humans in small case series with limited side effects [52]. Due to this limited experience and the fact that clinical studies on adjunctive NT-3 after meningitis are lacking, systemic NT-3 cannot be recommended for the use in humans with meningitis at this time.

With respect to changes in the brain, a benefit of adjunctive therapy with NT-3 or dexamethasone could not be observed: activation of astrocytes, for instance, reflected in GFAP-positive astrocytes, was not altered by adjunctive therapy. Gliosis occurs in response to all forms of CNS injury or disease. The functions of reactive astrocytes are not well understood and both harmful and beneficial activities have been attributed to these cells. However, we could not detect severe brain damage two weeks after infection in our model. Signs of parenchymal bleeding or axonal injury, which are typical findings of severe experimental murine meningitis, have not been observed as documented by negative iron staining of the brain $[53,54]$. The most likely explanation is the early start of antibiotic therapy at 18 hours after infection. This time frame was chosen because the focus of the study was on a possible treatment effect on hearing loss, requiring less-than-complete damage of the inner ear as observed when treatment is begun early (18 $\mathrm{h}$ after infection). A later start of antibiotic therapy in mice (e.g. $24 \mathrm{~h}$ after infection) results in an irreversible hearing impairment [55]. In addition, brain pathology is then more pronounced (e.g. damage of neurons, vasculitis, and ischemia) and mortality is higher $[53,54]$. Therefore, a possible effect of adjunctive therapy on pathological changes in the brain might have been missed in the current study.

The impact of long-term NT-3 therapy on long-term hearing loss was compared not only with placebo-treated animals but also with animals that received adjunctive therapy with dexamethasone, which has been recommended as the standard adjunctive therapy of choice in patients with pneumococcal meningitis $[34,56]$. Here, therapy with NT-3 was of clear benefit in comparison with adjunctive placebo and similar in effectiveness to adjunctive dexamethasone. Just recently, however, the benefit of dexamethasone in pneumococcal meningitis has been questioned by a large meta-analysis of individual patient data [57]. Currently, it is unclear how this observation will affect future treatment guidelines. This highlights the need for further adjunctive therapeutic approaches. At present, dexamethasone is not recommended in patients with immunosuppression and contraindications to corticosteroids. In such patients, adjunctive NT-3 therapy might be an interesting alternative to dexamethasone. At present, data on NT-3 therapy in pneumococcal meningitis is still experimental and experience on possible side effects of systemic NT-3 treatment as well as the high costs of NT-3 need to be kept in mind.

In conclusion, systemically applied NT-3 reached the spiral ganglion, leading to a reduced loss of spiral ganglion neurons. Furthermore, this neuroprotective agent had a positive impact on hearing thresholds. Compared with the currently established adjuvant therapy with dexamethasone, NT-3 showed similar effects. Systemic NT-3 could be a valid alternative to reduce damage to spiral ganglion neuronal cells and hearing loss after bacterial meningitis.

\section{List of abbreviations}

ABR: auditory brain-stem responses; $\mathrm{AHL}$ : age-related hearing loss; APP: amyloid precursor protein; BDNF: brain derived neurotrophic factor; cfu: colony forming units; Con: controls; CS: clinical score;

Dex: dexamethasone; EDTA: ethylenediaminetetraacetic acid; GC: ganglion cell; GFAP: glial fibrillary acidic protein; H\&E: haematoxylin and eosin; HT: hearing threshold; IgG: Immunoglobulin G; NT-3: Neurotrophin-3: PBS: phosphate buffered saline; Plc: placebo; PM: pneumococcal meningitis; SD: standard deviation; SGC: spiral ganglion cell; SP: Streptococcus pneumonia; SPL: sound pressure level; TrkB: tyrosine kinase receptor B; TrkC: tyrosine kinase receptor $C$.

\section{Acknowledgements}

We thank Prof. Dr. Sven Hammerschmidt (University of Greifswald, Greifswald, Germany) for providing the pneumococci. The project was financed by the Meningitis Research Foundation (MRF), which is highly appreciated. Also, we are grateful for the financial aid of the Deutsche Forschungsgemeinschaft (DFG), the University of Munich (FöFoLe), the Friedrich Baur Stiftung, and the Else Kroener Fresenius Foundation (EKFS)

\section{Author details}

'Department of Neurology, Klinikum Grosshadern, Ludwig Maximilians University Munich, Marchioninistrasse 15, 81377 Munich, Germany. ${ }^{2}$ Center of Neuropathology and Prion Research, Ludwig Maximilans University Munich, Feodor-Lynen-Strasse 23, 81377 Munich, Germany.

\section{Authors' contributions}

The work presented here was carried out in collaboration between all authors. Experimental procedures were carried out by MK and CD with technical assistance of BA. Histological assessment of slides was performed by $C D, M K, U K, A G$, and TH. The manuscript was drafted by CD and MK and discussed and edited by all co-authors. All authors have read and approved the final version of the manuscript.

\section{Competing interests}

The authors declare that they have no competing interests.

Received: 16 August 2010 Accepted: 24 January 2011

Published: 24 January 2011

\section{References}

1. Koedel U: Toll-like receptors in bacterial meningitis. Curr Top Microbiol Immunol 2009, 336:15-40 
2. Klein M, Koedel U, Kastenbauer S, Pfister HW: Nitrogen and oxygen molecules in meningitis-associated labyrinthitis and hearing impairment. Infection 2008, 36:2-14

3. Ramakrishnan M, Ulland AJ, Steinhardt LC, Moisi JC, Were F, Levine OS: Sequelae due to bacterial meningitis among African children: a systematic literature review. BMC Med 2009, 7:47.

4. Klein M, Schmidt C, Kastenbauer S, Paul R, Kirschning CJ, Wagner H, Popp B, Pfister HW, Koedel U: MyD88-dependent immune response contributes to hearing loss in experimental pneumococcal meningitis. J Infect Dis 2007, 195:1189-1193.

5. Klein M, Koedel U, Pfister HW, Kastenbauer S: Morphological correlates of acute and permanent hearing loss during experimental pneumococcal meningitis. Brain Pathol 2003, 13:123-132.

6. Merchant SN, Gopen Q: A human temporal bone study of acute bacterial meningogenic labyrinthitis. Am J Otol 1996, 17:375-385.

7. Klein M, Koedel U, Pfister HW: Oxidative stress in pneumococcal meningitis: a future target for adjunctive therapy? Prog Neurobiol 2006, 80:269-280.

8. Weber JR, Tuomanen El: Cellular damage in bacterial meningitis: an interplay of bacterial and host driven toxicity. J Neuroimmunol 2007, 184:45-52

9. van de Beek D, Farrar JJ, de Gans J, Mai NT, Molyneux EM, Peltola H, Peto TE, Roine I, Scarborough M, Schultsz C, et al: Adjunctive dexamethasone in bacterial meningitis: a meta-analysis of individual patient data. Lancet Neurol 9:254-263.

10. Paul R, Lorenzl S, Koedel U, Sporer B, Vogel U, Frosch M, Pfister HW: Matrix metalloproteinases contribute to the blood-brain barrier disruption during bacterial meningitis. Ann Neurol 1998, 44:592-600.

11. Kastenbauer $\mathrm{S}$, Klein M, Koedel U, Pfister HW: Reactive nitrogen species contribute to blood-labyrinth barrier disruption in suppurative labyrinthitis complicating experimental pneumococcal meningitis in the rat. Brain Res 2001, 904:208-217.

12. Winter AJ, Marwick S, Osborne M, Comis S, Stephen J, Tarlow M: Ultrastructural damage to the organ of corti during acute experimental Escherichia coli and pneumococcal meningitis in guinea pigs. Acta Otolaryngol 1996, 116:401-407.

13. Caye-Thomasen P, Worsoe L, Brandt CT, Miyazaki H, Ostergaard C, FrimodtMoller N, Thomsen J: Routes, dynamics, and correlates of cochlear inflammation in terminal and recovering experimental meningitis. Laryngoscope 2009, 119:1560-1570.

14. Meli DN, Coimbra RS, Erhart DG, Loquet G, Bellac CL, Tauber MG, Neumann U, Leib SL: Doxycycline reduces mortality and injury to the brain and cochlea in experimental pneumococcal meningitis. Infect Immun 2006, 74:3890-3896.

15. Tinling SP, Colton J, Brodie HA: Location and timing of initial osteoid deposition in postmeningitic labyrinthitis ossificans determined by multiple fluorescent labels. Laryngoscope 2004, 114:675-680.

16. Winter AJ, Comis SD, Osborne MP, Tarlow MJ, Stephen J, Andrew PW, Hill J, Mitchell $\mathrm{TJ}$ : A role for pneumolysin but not neuraminidase in the hearing loss and cochlear damage induced by experimental pneumococcal meningitis in guinea pigs. Infect Immun 1997, 65:4411-4418.

17. Miller JM, Chi DH, O'Keeffe $\amalg$, Kruszka P, Raphael Y, Altschuler RA Neurotrophins can enhance spiral ganglion cell survival after inner hair cell loss. Int J Dev Neurosci 1997, 15:631-643.

18. Nadol JB Jr, Young YS, Glynn RJ: Survival of spiral ganglion cells in profound sensorineural hearing loss: implications for cochlear implantation. Ann Otol Rhinol Laryngol 1989, 98:411-416.

19. Lyxell B, Andersson J, Andersson U, Arlinger S, Bredberg G, Harder H: Phonological representation and speech understanding with cochlear implants in deafened adults. Scand J Psychol 1998, 39:175-179.

20. Pisoni DB, Geers AE: Working memory in deaf children with cochlear implants: correlations between digit span and measures of spoken language processing. Ann Otol Rhinol Laryngol Suppl 2000, 185:92-93.

21. Yukawa K, Cohen L, Blamey P, Pyman B, Tungvachirakul V, O'Leary S: Effects of insertion depth of cochlear implant electrodes upon speech perception. Audiol Neurootol 2004, 9:163-172.

22. Fayad JN, Linthicum FH Jr: Multichannel cochlear implants: relation of histopathology to performance. Laryngoscope 2006, 116:1310-1320

23. Nadol JB Jr, Hsu WC: Histopathologic correlation of spiral ganglion cell count and new bone formation in the cochlea following meningogenic labyrinthitis and deafness. Ann Otol Rhinol Laryngol 1991, 100:712-716.
24. Nadol JB Jr: Patterns of neural degeneration in the human cochlea and auditory nerve: implications for cochlear implantation. Otolaryngol Head Neck Surg 1997, 117:220-228.

25. Fritzsch B, Tessarollo L, Coppola E, Reichardt LF: Neurotrophins in the ear: their roles in sensory neuron survival and fiber guidance. Prog Brain Res 2004, 146:265-278.

26. Lewin GR, Barde YA: Physiology of the neurotrophins. Annu Rev Neurosci 1996, 19:289-317.

27. Wise AK, Hume CR, Flynn BO, Jeelall YS, Suhr CL, Sgro BE, O'Leary SJ, Shepherd RK, Richardson RT: Effects of Localized Neurotrophin Gene Expression on Spiral Ganglion Neuron Resprouting in the Deafened Cochlea. Mol Ther 2010, 18(6):1111-22.

28. Ernfors P, Van De Water T, Loring J, Jaenisch R: Complementary roles of BDNF and NT-3 in vestibular and auditory development. Neuron 1995, 14:1153-1164.

29. Altschuler RA, Cho Y, Ylikoski J, Pirvola U, Magal E, Miller JM: Rescue and regrowth of sensory nerves following deafferentation by neurotrophic factors. Ann N Y Acad Sci 1999, 884:305-311.

30. Ernfors P, Duan ML, ElShamy WM, Canlon B: Protection of auditory neurons from aminoglycoside toxicity by neurotrophin-3. Nat Med 1996, 2:463-467

31. Staecker $H$, Kopke $R$, Malgrange B, Lefebvre $P$, Van de Water TR: NT-3 and/ or BDNF therapy prevents loss of auditory neurons following loss of hair cells. Neuroreport 1996, 7:889-894.

32. Richardson RT, Wise AK, Thompson BC, Flynn BO, Atkinson PJ, Fretwell NJ, Fallon JB, Wallace GG, Shepherd RK, Clark GM, O'Leary SJ: Polypyrrolecoated electrodes for the delivery of charge and neurotrophins to cochlear neurons. Biomaterials 2009, 30:2614-2624.

33. Shepherd RK, Coco A, Epp SB: Neurotrophins and electrical stimulation for protection and repair of spiral ganglion neurons following sensorineural hearing loss. Hear Res 2008, 242:100-109.

34. Chaudhuri A, Martinez-Martin P, Kennedy PG, Andrew Seaton R, Portegies P, Bojar M, Steiner I: EFNS guideline on the management of communityacquired bacterial meningitis: report of an EFNS Task Force on acute bacterial meningitis in older children and adults. Eur J Neurol 2008, 15:649-659.

35. Kim HH, Addison J, Suh E, Trune DR, Richter CP: Otoprotective effects of dexamethasone in the management of pneumococcal meningitis: an animal study. Laryngoscope 2007, 117:1209-1215.

36. Klein M, Koedel U, Pfister HW, Kastenbauer S: Meningitis-associated hearing loss: protection by adjunctive antioxidant therapy. Ann Neurol 2003, 54:451-458.

37. Noben-Trauth K, Zheng QY, Johnson KR: Association of cadherin 23 with polygenic inheritance and genetic modification of sensorineural hearing loss. Nat Genet 2003, 35:21-23.

38. Johnson KR, Zheng QY, Noben-Trauth K: Strain background effects and genetic modifiers of hearing in mice. Brain Res 2006, 1091:79-88.

39. Koedel U, Bayerlein I, Paul R, Sporer B, Pfister HW: Pharmacologic interference with NF-kappaB activation attenuates central nervous system complications in experimental Pneumococcal meningitis. J Infect Dis 2000, 182:1437-1445

40. Kuo LT, Simpson A, Schanzer A, Tse J, An SF, Scaravilli F, Groves MJ: Effects of systemically administered NT-3 on sensory neuron loss and nestin expression following axotomy. J Comp Neurol 2005, 482:320-332.

41. Alcala-Barraza SR, Lee MS, Hanson LR, McDonald AA, Frey WH, McLoon LK Intranasal delivery of neurotrophic factors BDNF, CNTF, EPO, and NT-4 to the CNS. J Drug Target 2010, 18:179-190.

42. Pettingill LN, Minter RL, Shepherd RK: Schwann cells genetically modified to express neurotrophins promote spiral ganglion neuron survival in vitro. Neuroscience 2008, 152:821-828.

43. Terayama Y, Kaneko K, Tanaka K, Kawamoto K: Ultrastructural changes of the nerve elements following disruption of the organ of Corti. II. Nerve elements outside the organ of Corti. Acta Otolaryngol 1979, 88:27-36.

44. McGuinness SL, Shepherd RK: Exogenous BDNF rescues rat spiral ganglion neurons in vivo. Otol Neurotol 2005, 26:1064-1072.

45. Dicou $E$, Masson C, Jabbour W, Nerriere V: Increased frequency of NGF in sera of rheumatoid arthritis and systemic lupus erythematosus patients. Neuroreport 1993, 5:321-324.

46. Bonini S, Lambiase A, Angelucci F, Magrini L, Manni L, Aloe L: Circulating nerve growth factor levels are increased in humans with allergic diseases and asthma. Proc Natl Acad Sci USA 1996, 93:10955-10960. 
47. Azar ST, Major SC, Safieh-Garabedian B: Altered plasma levels of nerve growth factor and transforming growth factor-beta2 in type-1 diabetes mellitus. Brain Behav Immun 1999, 13:361-366.

48. Quarcoo D, Fischer TC, Peckenschneider N, Groneberg DA, Welker P: High abundances of neurotrophin 3 in atopic dermatitis mast cell. $J$ Occup Med Toxicol 2009, 4:8.

49. Gadient RA, Cron KC, Otten U: Interleukin-1 beta and tumor necrosis factor-alpha synergistically stimulate nerve growth factor (NGF) release from cultured rat astrocytes. Neurosci Lett 1990, 117:335-340.

50. Tsao D, Thomsen HK, Chou J, Stratton J, Hagen M, Loo C, Garcia C, Sloane DL, Rosenthal A, Lin JC: TrkB agonists ameliorate obesity and associated metabolic conditions in mice. Endocrinology 2008, 149:1038-1048.

51. Apfel SC: Neurotrophic factors in peripheral neuropathies: therapeutic implications. Brain Pathol 1999, 9:393-413.

52. Sahenk Z, Nagaraja HN, McCracken BS, King WM, Freimer ML, Cedarbaum JM, Mendell JR: NT-3 promotes nerve regeneration and sensory improvement in CMT1A mouse models and in patients. Neurology 2005, 65:681-689.

53. Klein M, Paul R, Angele B, Popp B, Pfister HW, Koedel U: Protein expression pattern in experimental pneumococcal meningitis. Microbes Infect 2006, 8:974-983.

54. Nau R, Gerber J, Bunkowski S, Bruck W: Axonal injury, a neglected cause of CNS damage in bacterial meningitis. Neurology 2004, 62:509-511.

55. Kesser BW, Hashisaki GT, Spindel JH, Ruth RA, Scheld WM: Time course of hearing loss in an animal model of pneumococcal meningitis. Otolaryngol Head Neck Surg 1999, 120:628-637.

56. Tunkel AR, Hartman BJ, Kaplan SL, Kaufman BA, Roos KL, Scheld WM, Whitley RJ: Practice guidelines for the management of bacterial meningitis. Clin Infect Dis 2004, 39:1267-1284.

57. van de Beek D, Farrar JJ, de Gans J, Mai NT, Molyneux EM, Peltola H, Peto TE, Roine I, Scarborough M, Schultsz C, et al: Adjunctive dexamethasone in bacterial meningitis: a meta-analysis of individual patient data. Lancet Neurol 2010, 9:254-263.

doi:10.1186/1742-2094-8-7

Cite this article as: Demel et al:: Reduced spiral ganglion neuronal loss by adjunctive neurotrophin-3 in experimental pneumococcal meningitis. Journal of Neuroinflammation 2011 8:7.

\section{Submit your next manuscript to BioMed Central and take full advantage of:}

- Convenient online submission

- Thorough peer review

- No space constraints or color figure charges

- Immediate publication on acceptance

- Inclusion in PubMed, CAS, Scopus and Google Scholar

- Research which is freely available for redistribution 